\title{
ANTIMICROBIAL BIO-NONWOVEN FABRICS FOR EYES'S SWATH AND DIAPERS FOR INFANT'S INCUBATORS
}

\author{
EISayed A. EINashar \\ Faculty of Specific Education, Kafrelsheikh University \\ El-Geish Street, 33516, Kafrelshekh City, Egypt \\ e-mail:smartex@kfs.edu.eg
}

\begin{abstract}
An infant incubator is a piece of equipment common to pediatric hospitals, birthing centers and neonatal intensive care units. While the unit may serve several specific functions, it is generally used to provide a safe and stable environment for newborn infants, often those who were born prematurely or with an illness or disability that makes them especially vulnerable for the first several months of life. The objective of this research was to gain a better understanding of New Approach for a Bio-Nonwoven fabrics and infant's incubator in terms of the specific materials as MaterBi/PCL $\Theta$ as Bioplastic and the elements of comfort, drivers associated with it and its waste biodegradation by different methods. Shortly after birth, the beginning in first hours of life babies with neonatal, a byproduct of the red blood cells decomposition. Many convenient features to consider with tow basic disposable eyes' swathe and diapers on infant's incubator options: cloth of basic disposable eyes' swathe and diapers, with their end use properties. The form design of eyes'swathe ${ }^{\circledR}$ and diapers $\AA$ shapes, for infant's incubator stage then consider convenience, cost, and environmental waste.
\end{abstract}

Keywords: Bio-Nonwoven, incubator, eye's swathe, diapers.

\section{INTRODUCTION:}

Perhaps the most obvious function of an infant incubator is to protect infants during the earliest stage of life, when they're most vulnerable. As fully enclosed and controllable environments, incubators can be used to protect babies from a wide range of possible dangers, according Incubators which are fully temperature controlled, shielding infants from harmful cold, and they provide insulation from outside noise, making it easier for them to get plenty of comfortable rest. Incubator environments can be kept sterile, protecting infants from germs and minimizing the risk of infection. The enclosure also keeps out all airborne irritants like dust and other allergens. The cradle of the incubator is a roomy and comfortable surface, so it's possible to leave the infant in place while many examinations and even simple medical procedures are administered. This protects infants from too much handling, which can be a concern in the case of some premature births. Due to the growing demand for comfortable, clean, and hygienic textile goods, an urgent need for production of antimicrobial textile goods has arisen. With the advent of new technologies, the growing needs of consumers in terms of health and hygiene can be fulfilled without compromising issues related to safety, human health, and the environment [1]. The use of elemental silver as an anti-bacterial agent is nearly as old as the history of mankind. The ancient Egyptians mention the medicinal use of silver in their writings [1].

The Egyptian environment has covered the babies' health and financial savings. We are still not finished; the health of the planet is also compromised by the use of disposable diapers. Approximately two million of disposable eyes' swathe and ten billion diapers end up in Egypt landfills every year. It is unknown exactly how longs it will take disposable diapers to decompose but estimates are in the 100.s of years [12]. As the textile industry in the Egypt struggles, due to heavy competition from global sources, the $s$ industry is growing and

IRITIE Vol. 4, No. 4, 2016 ISSN 1314-8788 (print), ISSN 1314-8796 (online), doi: 10.15547/artte.2016.04.003 


\section{ART'TLE}

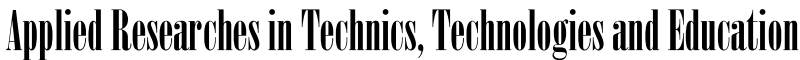

Journal of the Faculty of Technics and Technologies, Trakia University https://sites.google.com/a/trakia-uni.bg/artte/

prospering, as a result, Innovation is the key for medical s producers to stay competitive in today's market. Possible improvements may include improved barrier protection, improved strength and comfort, and improved production speed of medical. There are many reasons, and more specifically, $s$ with synthetic fibres has grown in use over the past few years. Overall, these two products, adult and children's diapers represent a significant portion of the $s$ industry. Medical textiles use all types of textile fabrications, including knits, wovens, and each type of construction offers unique properties that are useful to various medical applications. Environment-friendly polymeric materials are classified into two categories: degradable synthetic polymers (polycaprolactone, polylactide, polyvinyl alcohol, and polyesteramide) and renewable natural polymers (chitin, chitosan, pectin, starch, and cellulose). Among these, starch is the most attractive candidate because it exists abundantly in nature and is very inexpensive. For these reasons, starch has been used widely in the food, textile, and paper industries [11]. Starch-based biodegradable plastic materials can be prepared by various methods: embedding granular or gelatinized starch in synthetic polymeric matrices such as polyethylene, polypropylene, polystyrene, and polyvinyl chloride [3]; blending starch with a hydrophilic polymer, foaming starch within an extruder, and preparing thermoplastic starch by melting under high temperature and pressure. When incorporated with a synthetic polymer, the synthetic polymer will remain in an undegraded state even after the starch is biodegraded. When blended with other polymeric materials, phase separation mayoccur, causing reduction of mechanical properties. In addition, there are disadvantages when starch is used as a major component, such as inferior mechanical properties due to brittleness and limitation of usage due to the hydrophilicity. Polyurethanes are polymeric materials with urethane linkages along the backbone, and they are prepared by polyaddition polymerization between polyisocyanates and polyols. Polyurethanes with various chemical, mechanical, and degradation properties can be prepared in molded article, film, fiber, foam, and emulsion forms according to the nature of the polyisocyanates and polyols used. Polyurethanes have been widely used in industry as fibers, elastomers, adhesives, and coatings. In particular, polyurethane foams are used widely in many fields as structural, cushioning, insulational, electrical, flotational, and packaging materials [11].

Natural and synthetic fibres vary greatly in their responses to microbial growth. Both may act as willing substrates but the mechanism in the two cases is very different. Natural fibres are easy targets for microbial attack because they retain water readily, and microbial enzymes can readily hydrolyse their polymer linkages. Cotton, wool, jute, and flax are reported to be most susceptible to microbial attack. If 105 colonies in $1 \mathrm{ml}$ water are applied to approximately $0.5 \mathrm{~g}$ cotton, after a few hours a logarithmic growth is observed and the population increases from 105 to 109 colonies. The damage caused by the fungus Aspergillus niger on cotton has been extensively investigated by Ucarci and Seventekin. They found that there were differences in the strength of cotton as the time, temperature, $\mathrm{pH}$, and medium conditions changed. Within natural fibres too, the persistence period varied greatly [17].

The industry in the Egypt is a fairly new industry, as compared to wovens and knits, and is proving to be sustainable industries appear to demonstrate all levels in that it offers economically viable and environmentally responsible products, as well as serve a social need [7]. Medical textiles, as a product, bring many benefits to multiple industrial and consumer markets, such as, hygiene industry, and most importantly of Biodegradable polymers may be defined as a group of materials that respond to the action of enzymes or from chemical degradation associated with interaction with living organisms. Biodegradation may also occur through chemical reactions that are initiated by photochemical processes, oxidation and hydrolysis that result from the action of environmental factors [12]. Target markets for Bioplastic (BPs) include packaging materials (trash bags, wrappings, loose-fill foam, food containers, film wrapping, laminated paper), disposable nonwovens (engineered

\section{IRTTIE Vol. 4, No. 4, 2016 ISSN 1314-8788 (print), ISSN 1314-8796 (online), doi: 10.15547/artte.2016.04.003}




\section{ARTTE $Y^{2}$}

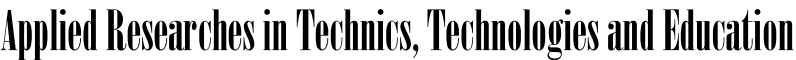

Journal of the Faculty of Technics and Technologies, Trakia University https://sites.google.com/a/trakia-uni.bg/artte/

fabrics) and hygiene products (diaper back sheets, cotton swabs), consumer goods (fastfood tableware, containers, egg cartons, razor handles, toys), and agricultural tools (mulch films, planters). BP commercialization is however, hampered by competition with commodity plastics that are inexpensive and familiar to the customer. According to the association of nonwovens fabric industry, a nonwoven is defined as "a sheet or web structure bonded together by entangling fiber or filaments mechanically, thermally or chemically. They are flat, porous sheets that are made directly from separate fibers or from molten plastic or plastic film. Nonwoven fabrics that can be engineered to have a limited life be a single-use fabric, or a very durable fabric can, provide specific functions (e.g., absorbency, liquid repellency, resilience, stretch, softness, strength, flame retardancy, washability, cushioning, filtering, bacterial barrier, sterility).In addition, the machinery used to produce nonwovens are becoming cheaper, making the s industry appealing to entrepreneurs worldwide. Engineering expertise has become intrinsic to the technology, greatly diminishing the need for a large support staff [14]. Physical properties of Mater-Bi materials are shown as described by). [8]. Starch-based BPs ${ }^{\circledR}$ can be produced by blending or mixing them with synthetic polymers. By varying the synthetic blend component and its miscibility with starch, the morphology and hence the properties can be regulated easily and efficiently. Novamont has successfully implemented this approach under the Mater-Bi® trademark [10]. Blends containing thermoplastic starch (destructurized starch that is noncrystalline, produced by the application of heat and work) may be blended or grafted with biodegradable polyesters [such as polycaprolactone (PCL)] to increase flexibility and resistance to moisture. These materials are mainly formed into films and sheets. Blends with more than $85 \%$ starch are used for foaming and injection moulding. The foams can be used as loose-fill in place of polystyrene; the starch-based loose fills have an average density of 6 to $8 \mathrm{~kg} / \mathrm{m} 3$, compared with $4 \mathrm{~kg} / \mathrm{m} 3$ for expanded polystyrene loose fill [18]. Loose-fill materials from starch are generally water sensitive. This is a problem if the packaging materials are exposed to water, but an advantage when down-the-drain disposal is desired. By mixing thermoplastic starch with cellulose derivatives, rigid and dimensionally stable injection-moulded articles result. Poly $(\varepsilon-$ caprolactone), PCL is thermoplastic biodegradable polyester synthesized by chemical conversion of crude oil, followed by ring-opening polymerization. PCL has good water, oil, solvent, and chlorine resistance, a low melting point, and low viscosity, and is easily processed thermally. To reduce manufacturing costs, PCL may be blended with starch for example, to make trash bags. By blending PCL with fibre forming polymers (such as cellulose), hydrogen-tangled $\mathrm{s}$ (in which bonding of a fibre web into a sheet is accomplished by entangling the fibers by water jets), scrub-suits, incontinence products, and bandage holders have been produced [19].

The object of this work: establish a design as a new branch of eyes' swathe and diapers shapes basic disposable eyes' swathe and diapers on infant's incubator options, enhance the understanding medical textiles of Bio-Nonwoven fabrics production by mapping a product textile from the manufacturing of the product to the end customer. Moreover, to increase competitiveness of the medical textiles of Bio-Nonwoven fabrics industry in the Egypt.

\section{MATERIALS AND PROCEDURE}

This experimental work was conducted to produce a new design and form of eye's swathe and diapers by using Bio-Nonwoven fabric (MaterBi/PCL $($ ) $)$. This prototype is suitable for the end use of infant's incubator. The source of MaterBi/PCL® as Bioplastic film® was obtained from Dr. R.-J. Mueller at Gesellschaft für Biotechnologische Forschung mbH), Braunschweig, Germany. Measurements for newborn was experimented according to the American Standard of Textile Measurement (ASTM) Standards D4910-07[6]: head (circumference) = 


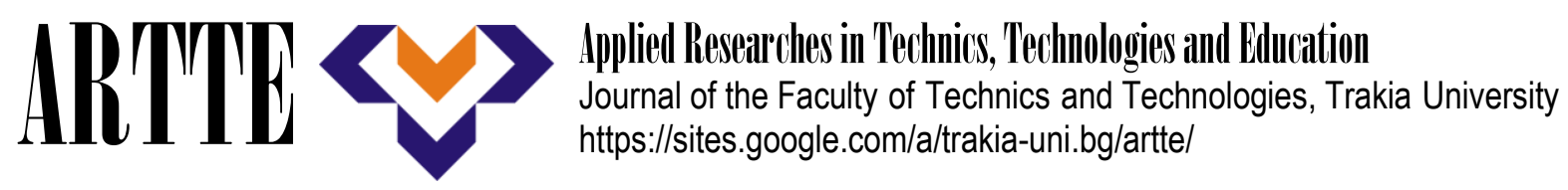

$38.74 \mathrm{~cm}$, Total crotch length $=27.31 \mathrm{~cm}$, hip heigh $\mathrm{t}=21.27 \mathrm{~cm}$, waist height $=26.99 \mathrm{~cm}$, centre back waist length $=14.61 \mathrm{~cm}$, centre front waist length $=13.97 \mathrm{~cm}$.

\subsection{Description of Eyes`Swath Model}

The absorbent polymer being applied on the surface of the desired area and substantially even layers. These desired surface and multi-layers form a reactive composition, which can be fuse and bear temperature in the range of 90 and 205\% $F$. The type of end-use will determine the thickness of the layer applied to the substrate, and the core becomes oversaturated, and the tape tabs could be added. The detailed structures of eyes' swath model for two and three dimensions are shown in Figure 1 (b) and (c), respectively.

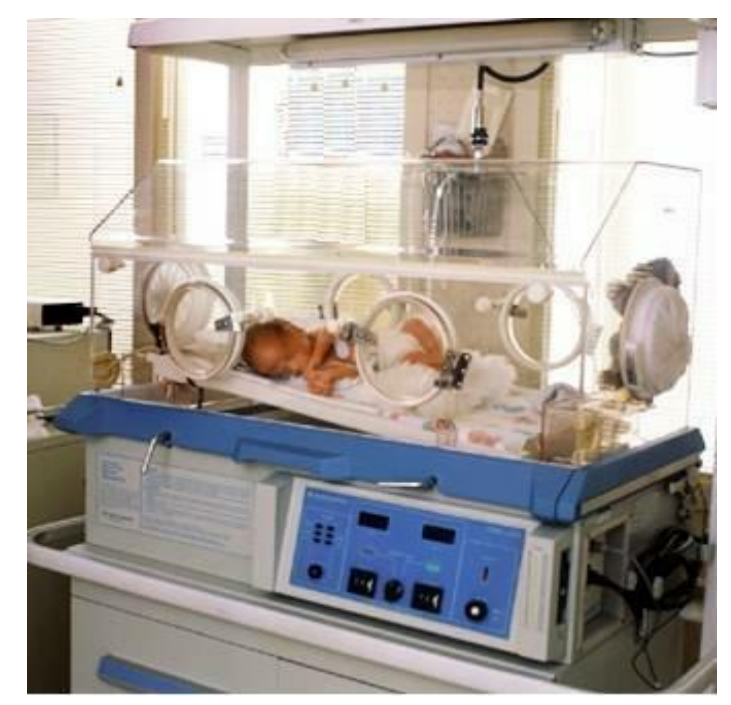

Figure 1a. Infant icubator

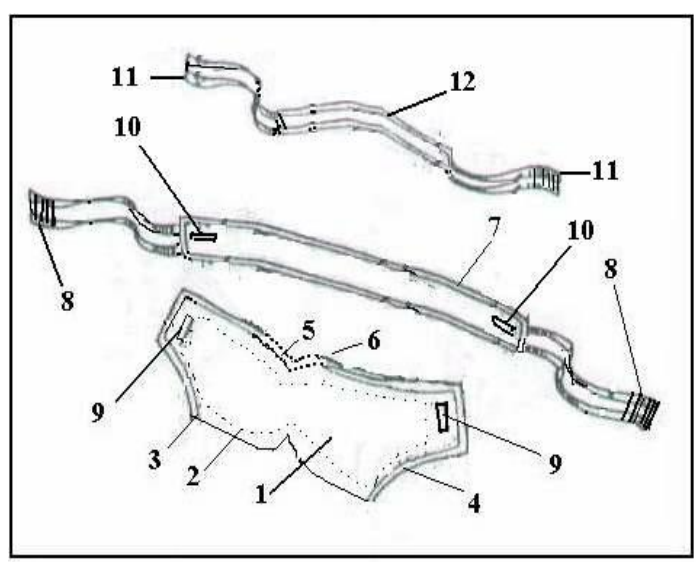

Figure $1 b$.

The structure of eyes' swath 


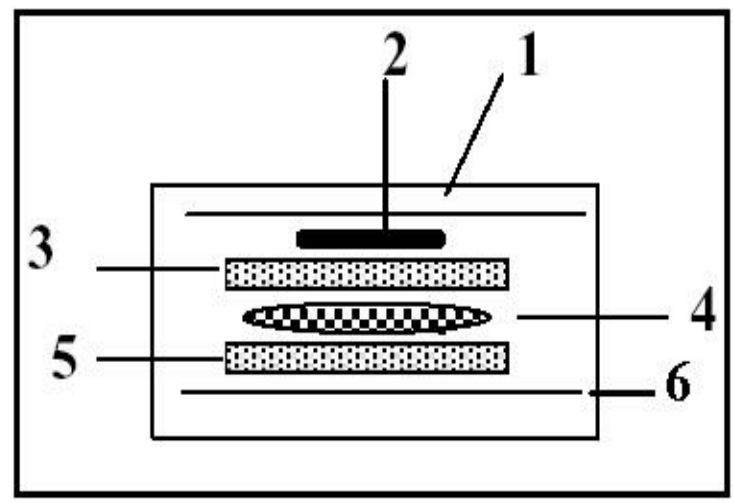

Figure 1c. Hygienic Diaper model

The structure of eyes' swath in Figure 1b:

1- MaterBi/PCL® as cover for reflection light without porous;

2- Black layer for obstacle light;

3- Superior layer for water-impermeable by low bulk density porous;

4- Tissue with low density of porous;

5- Absorbance core for the perspiration may be constitutes from dust cotton;

6- MaterBi/PCL® forms the lower layer;

7- Belt behind and surroundings the head;

8- Strip of adhesive;

9- Hole for tightens the eye's swathe belt behind the head.

10- Hole for tightens the upper and surrounding belt.

11- Strip of adhesive;

12- Belt upper and surroundings the head.

\subsection{Description of the hygienic Diaper model}

A satisfactory absorbent device for use in the type of incontinence where large volumes of urine are suddenly discharged must be able to absorb and retain this urine rapidly, so, especially in the case of adult incontinent [10]. New designs in cloth diapers have gathered legs, require no folding, and use no pins. Diapers may have up to six layers of thickness down the middle. Fitted or contour diapers have an hourglass shape, require no pins, and come in one sizes, diapers may look for ones design. Instead of pins, also consider waterproof pants. Pull-on or snap-on styles are easy to use and keep outer clothing and bedding dry. Diaper wraps or covers use snaps and closures so diaper pins are not needed. Both come in whit of colour designs. We used the hygienic change model as shown in the structure below [10]:

In Figure 1C:

1- MaterBi/PCL $\AA$ as cover [15];

2- White tissue layer for obstacle light (dark colour filter more UV rays than white or light colour);

3- Superior layer for water-impermeable by low bulk density porous;

4- Absorption core form dust of cotton;

5- Absorption of Tissue with lower density of porous;

6- MaterBi/PCL® Lower layer of Tissue. 


\section{ARTTIE $Y$}

Ipplied Reseitrones in Technics, Technologies and Bductition

Journal of the Faculty of Technics and Technologies, Trakia University https://sites.google.com/a/trakia-uni.bg/artte/

Characterized and then stretched in two directions to various strain levels, and measured to determine the effect of deformation on pore structure and transport properties. Typical microstructures of a top layer on the melton blown fabric and of the melton blown fabric of polymer solution from were used to observe the changes in pore/fiber structure at different strain levels. Pore size was determined in a capillary liquid expulsion porometer. Airflow was also measured in the capillary porometer. Aerosol filtration was measured with a solid salt aerosol. An elastic knit spandex fabric was also tested to allow comparison with another highly elastic and tough material used in clothing applications.

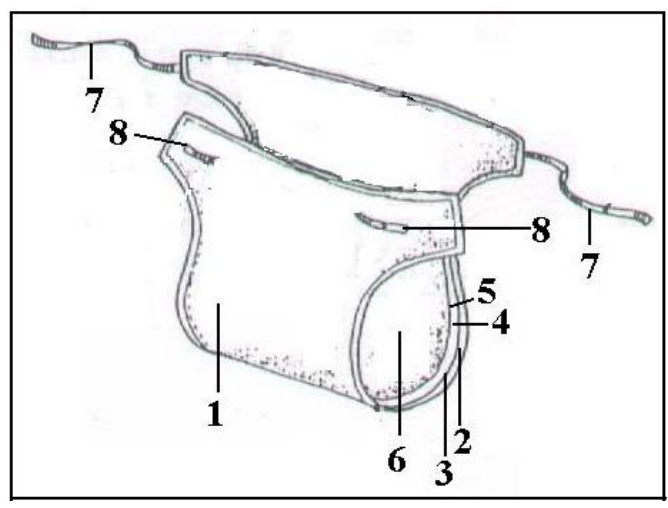

a

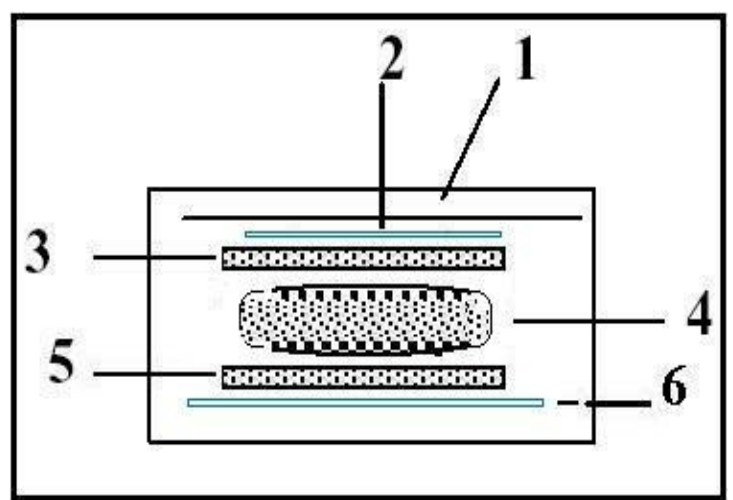

b

Figure 2. Model structure of diaper in 2D at (a), and (b) 3D

Experiments were carried out on woven fabrics, which were constructed according to the setting theory. Broad One warp yarn of $100 \%$ cotton and 20 Tex will be used, and filling yarns count of 40 Tex. The fabrics will be woven, fabrics specification on loom: end density, 1/inch: 93, Pick density, 1/inch: 46.72, fabric weight, $\mathrm{g} / \mathrm{m} 2: 200$. Fabric samples were woven on a Picanol weaving machine under equal technological conditions in the college of textiles, North Carolina State University. Woven fabrics are being fully characterized for those properties that may relate to comfort when used for apparel. Correlations with structure variables will be determined. Initial testing includes esthetical studies yarns tensile, weight, thickness (electronic thickness tester), and stiffness properties measures according to ASTM Standard Test Method. [1, 3, 4, 5]

\subsection{Evaluation of Stiffness}

The woven fabrics stiffness as a prime factor in determining the level of effective stiffness properties such as bending as shown in table (1). The measurement of stiffness of woven fabrics has been carried out according to standard test method ASTM. [5,6] By using Tester, for the determination of the thickness of a compressible material such stretch woven fabrics. by the sag of a projecting strip of sample [9].In his described of the stiffness testing by Shirley stiffness tester, in faculty of textiles NCSU,

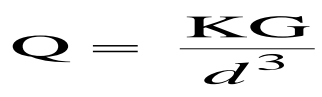

When $\mathrm{Q}=$ bending modulus, $\mathrm{G}=$ flexural rigidity, $\mathrm{d}=$ thickness, $\mathrm{K}=\mathrm{a}$ constant. 


\section{ARTTIE $Y$}

Ipplied Researlohes in Technics, Technologies and Bductition

Journal of the Faculty of Technics and Technologies, Trakia University https://sites.google.com/a/trakia-uni.bg/artte/

\section{RESULTS AND DISCUSSION}

Biodegradable polymers may be defined as a group of materials that respond to the action of enzymes or from chemical degradation associated with interaction with living organisms. Target markets for BPs include packaging materials, disposable s (engineered fabrics) and hygiene products. Bioactive environments must be developed and will require capital investments. Results in Table (1) indicate, physical properties of diaper which is comfort for infants incubators. Our design is in agreement with standard measurements of American Standard of Textile Measurement (ASTM) Standards D4910-07 [5,6].

\subsection{Prediction of Diaper Wicking}

Pore size, air, water vapor, are the factors of transport properties and size of diaper Measurements which are elastic, design form, and weight, Thickness of the layers coating has also been found to affect aerosol filtration was used in protective clothing. In a porous nonwoven fabric of diaper, the mean pore size can be used to characterize fluid transfer phenomena and material's surface wetting tension. The pore size could be derived theoretically introducing a channel model, i.e., applicable for a simple nonwoven web of diaper structure. However, it has a limitation in the application for complex fabric structures of diaper in which we should consider not only the interstitial spaces between fibers but also those between yarns for the modeling. Experimentally, pore size distribution can be derived by stepwise measurements of fluid sorption amount at differently controlled capillary pressures each of which corresponds to critical pore size for the sorption. It is a time consuming work requiring an expensive experimental device. To measure the capillary rise, a scaled film was attached to the transparent wax paper plate. Under appropriate illumination, capillary rise front through diaper fabric between the MaterBi/PCL could be clearly seen. Capillary rise measured at the different positions along the width of fabric were averaged to calculate capillary pressure.

$$
V(C)=\left[\pi V_{o}(1+\varphi C)+\frac{\varphi C}{\varphi \tau}\right] / V_{C} \frac{\varphi C}{\varphi \rho}
$$

Where: $C=$ concentration, $\rho=$ position, $T=$ time, $V=$ diffusion coefficient, $V_{0}=$ initial diffusion. Coefficient and $\varphi=$ non-linearity. Because this type of diffusion Equation cannot be solved analytically in the case of three or three-layered of diaper, we solve this numerically by using the

$$
F=M\left[\frac{\varphi C}{\varphi \tau}\right]+d C
$$

Where: $F=$ Formulation for the time domain, $M=$ capacitance matrix; $d$ = diffusion coefficient conductance) matrix; $\mathrm{F}=$ Flux Factor; And $\mathrm{C}=$ nodal point concentration (solution),

$$
F=\left(\frac{1}{2}[d]^{(n)}+\frac{1}{\sum \tau}[M]\right)[c]^{n+1}
$$

We suggest that even though a material of diaper may have high surface energy, bulkiness of the structure (large pore size) will cause the capillary pressure to be low. 


\section{IRTITE Ipplied Researrches in Technics, Technologies and Cduciation Journal of the Faculty of Technics and Technologies, Trakia University https://sites.google.com/a/trakia-uni.bg/artte/}

\subsection{Vertical Wicking Diaper}

In order to rationalize the results of vertical wicking diaper (VWD), and then integrating with initial condition of $\mathrm{h}=0$ at $\mathrm{t}=0$, we get, thus theoretical Equation was developed as follows.

$$
V W D=\sqrt{\frac{2 k_{s \rho g h_{O}}}{\eta h}} \tau^{1 / 2}\left(\frac{1}{2}[d]^{(n)}+\frac{1}{\Sigma \tau}[M]\right)[c]^{n+1}
$$

Where: $h_{O}$ is the maximum vertical wicking diaper rise at the equilibrium state.

Table 1. Prototype Structure of Eyes' Swath and Diaper.

\begin{tabular}{|c|c|c|c|c|c|c|c|c|c|c|c|c|c|c|c|c|}
\hline & \multicolumn{8}{|c|}{ Eyes`swath structure parameters } & \multicolumn{8}{|c|}{ diaper structure parameters } \\
\hline $\begin{array}{l}\text { Physical } \\
\text { properties }\end{array}$ & 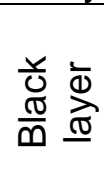 & $\sum_{\infty}$ & $\begin{array}{l}\text { 흐 } \\
\bar{\Phi} \\
\stackrel{\circ}{7} \\
\text { ஸे }\end{array}$ & ১) & 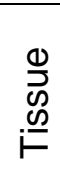 & 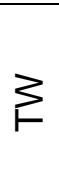 & $\frac{1}{0}$ & 3 & 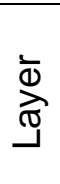 & 3 & 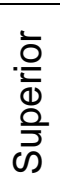 & 文 & 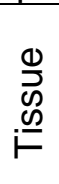 & 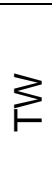 & ఫัँ & 3 \\
\hline $\begin{array}{l}\text { Thickness } \\
\mathrm{mm}\end{array}$ & 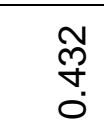 & $\begin{array}{l}\bar{\infty} \\
\infty \\
\stackrel{2}{\infty}\end{array}$ & 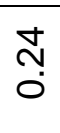 & N & $\frac{m}{n}$ & $\stackrel{\sim}{\stackrel{\sim}{*}}$ & $\begin{array}{l}\mathscr{Q} \\
\mathscr{\sigma}\end{array}$ & $\stackrel{\varphi}{\dot{f}}$ & 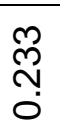 & ம & 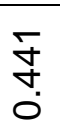 & $\begin{array}{l}\infty \\
\infty \\
\infty\end{array}$ & $\mathscr{\sigma}_{0}$ & $\stackrel{m}{\sim}$ & $\stackrel{\gamma}{\dot{\gamma}}$ & $\stackrel{\varphi}{\dot{f}}$ \\
\hline $\begin{array}{l}\text { Weight } \\
\mathrm{gm} / \mathrm{m} 2\end{array}$ & 옴 & & ヘิ & & $\begin{array}{l}\infty \\
\infty \\
\infty\end{array}$ & & 官 & & $\begin{array}{l}\mathscr{0} \\
\infty \\
\infty\end{array}$ & & ผें & & $\begin{array}{l}\infty \\
\dot{q} \\
\dot{q}\end{array}$ & & $\stackrel{\text { மீ }}{+}$ & \\
\hline $\begin{array}{l}\text { Pore size } \\
\text { (max,min) } \\
\mu \mathrm{m}\end{array}$ & $\begin{array}{l}\hat{N} \\
\text { Ò }\end{array}$ & & $\stackrel{i}{N}$ & & $\infty$ & & $\begin{array}{l}0 \\
\dot{0} \\
\stackrel{m}{-}\end{array}$ & & $\begin{array}{l}\text { N̦ } \\
\text { के }\end{array}$ & & $\stackrel{\infty}{\infty}$ & & $\stackrel{\infty}{\infty}$ & & مొ & \\
\hline & $\stackrel{\Upsilon}{\mp}$ & & $\underset{0}{0}$ & & $\begin{array}{l}\mathscr{0} \\
\stackrel{\sim}{N}\end{array}$ & & $\frac{0}{5}$ & & 仓ิ & & 운 & & م્ & & $\begin{array}{l}\text { ¿ } \\
\text { ச் }\end{array}$ & \\
\hline $\begin{array}{l}\text { Watervapour } \\
\text { Permeability }\end{array}$ & $\begin{array}{l}\hat{O} \\
0\end{array}$ & & $\overline{0}$ & & $\sim$ & & ஜి & & $\begin{array}{l}\hat{0} \\
\text { Oे }\end{array}$ & & 5 & & $\stackrel{\sim}{N}$ & & ஓे & \\
\hline $\begin{array}{l}\text { Light } \\
\text { permeability }\end{array}$ & 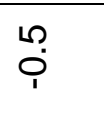 & & $\frac{⿱}{5}$ & & $\begin{array}{l}0 \\
0 \\
\end{array}$ & & : & & 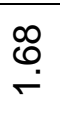 & & $\stackrel{\sim}{\check{r}}$ & & $\stackrel{\mathscr{O}}{\leftarrow}$ & & $\frac{\text { \% }}{\text { c }}$ & \\
\hline Stiffness & $\begin{array}{l}\stackrel{N}{N} \\
\stackrel{n}{n}\end{array}$ & & $\overline{0}$ & & $\begin{array}{l}\dot{J} \\
\dot{m}\end{array}$ & & $\stackrel{N}{\stackrel{N}{N}}$ & & হি & & $\frac{n}{6}$ & & $\begin{array}{l} \pm \\
\dot{~}\end{array}$ & & 동 & \\
\hline
\end{tabular}




\section{ART'TE Ipplied Resererches in Technics, Technologies ind Pducition Journal of the Faculty of Technics and Technologies, Trakia University https://sites.google.com/a/trakia-uni.bg/artte/}

The Simulation results are analyzed by non-linear diffusion model using finite element method (FEM), of Vertical Wicking Diaper (VWD), and water absorption in diaper by a Nonlinear Model using ABAQUS finite element method (AFEM), Therefore it is expected that a non-linear model may also be applicable to the three-layered system. A model for the analysis is shown in Figure 9. The diffusion Equation is as follows:

Where $u=$ concentration, $z=$ position, $\tau=$ time, $D=$ diffusion coefficient, $D_{0}=$ initial diffusion coefficient and $\sigma=$ non-linearity. Because this type of diffusion Equation cannot be solved analytically in the case of three-layered body problem, we solve this numerically by using the Equations $(6,7)$.

Physical properties of Mater-Bi materials,are:thickness=(0.29),Fabric weight $(\mathrm{g} / \mathrm{cm} 2)=(12.90)$, Vertical Wicking Diaper $($ dyne $/ \mathrm{cm})=0.12$. And calculated the Integrated of Diaper Structure (IDS) as following Equation.

$$
\mathrm{IDS}=\sum V W D(\text { layers }) / n(\text { layers })
$$

Where: $V W D$ Vertical Wicking Diaper (dyne/cm), $\mathrm{n}=$ number of layers. And the Total Vertical Wicking Diaper $($ dyne $/ \mathrm{cm})=(29.6+19.81+42.3+44.6) / 4=136.31 / 4=34.0775$ in figure 3 ,By appropriate conversion of the quantities used in Equation (6) and use of the calculated Integrated of Diaper Structure (IDS) , areas we can obtain the following Equation for the Volume Vertical Wicking Diaper, which can be practically applied:

$$
\begin{gathered}
V_{V W D}=\left(I S D\left(\frac{\Sigma(1-\pi W L)}{\pi(\text { front }+ \text { back })}\right)+\left(\frac{1}{\Sigma \pi 2 C L+H H+W H}\right)^{n+1}\right) \times 1 / I D S \\
V_{V W D}=86.65 \%
\end{gathered}
$$

Experimented Measurement according to (ASTM) Standards D4910-07 [4] as follows: CL = crotch length $=27.31 \mathrm{~cm}, \mathrm{HH}=$ hip height $=21.27 \mathrm{~cm}, \mathrm{WH}=$ waist height $=26.99 \mathrm{~cm}, \mathrm{WL}=$ centre back waist length $=14.61 \mathrm{~cm}(+)$ centre front waist length $=13.97 \mathrm{~cm}$. Head (circumference) $=38.74 \mathrm{~cm}$, Total crotch length $=27.31 \mathrm{~cm}$, hip height $=21.27 \mathrm{~cm}$.

Water absorption perpendicular to the nonwoven fabric in three-and multi-layered diaper nonwoven fabrics was measured using the pressure method. The results were obtained as follows: Water absorption perpendicular to the diaper nonwoven fabrics plane can be measured and evaluated using pressure method with good precision and easy handling. In single-layer diaper nonwoven fabrics, water-absorption properties can be evaluated by $\mathrm{W}$ the water, Absorption rate constant, and Mmax, the maximum water absorption. In the measurement of three-layered diaper nonwoven fabrics, Transient water-absorption behaviour is divided into three types for various combinations of fibre materials. The absorption behaviour in three-layered diaper nonwoven a non-linear diffusion model explains fabrics. 


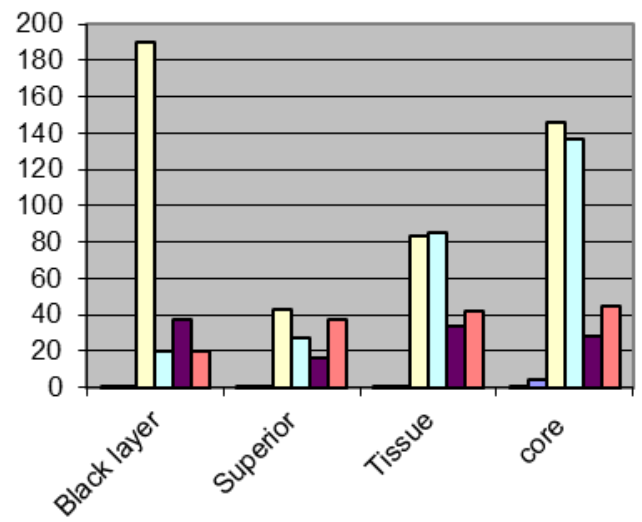

Diaper Structure Parameters

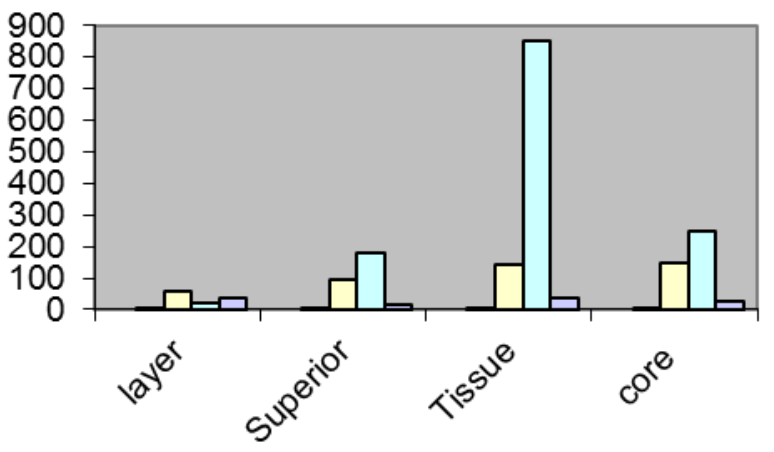

Figure 3: Illustrating the relationship of layers between eyes` swath at left and diaper structure at right.

\subsection{Antimicrobial agent based on silver}

Silver kills bacteria by strangling them in a warm and moist environment [2, 16]. Highly bioactive silver ions bind with proteins inside and outside bacterial cell membranes, thus inhibiting cell respiration and reproduction. Silver is 3-4 times more active at $\mathrm{pH} 8$ than at $\mathrm{pH}$ 6. Silver products are effective Various techniques have been explored to attach silver to textile materials. To prepare antimicrobial fabrics suitable for sterilisation of air, cellulose was grafted with acrylic acid and treated with silver nitrate to bind the silver ions to the $\mathrm{COOH}$ group of graft copolymer [13].

\subsubsection{Nano silver}

Nano silver is a powerful and natural antimicrobial agent that has been proven highly effective in fighting a whole range of microbes. Acting as a catalyst, it reportedly disables the enzyme that one-celled bacteria, viruses, and fungi need for their oxygen intake without

IRTIIE Vol. 4, No. 4, 2016 ISSN 1314-8788 (print), ISSN 1314-8796 (online), doi: 10.15547/artte.2016.04.003 
causing corresponding harm to human enzymes or other parts of the human body chemistry. The result is the destruction of disease-causing organisms without any detrimental effects on the surrounding human tissue.

\subsubsection{Preparation of fabric}

Desizing. The grey fabric is desized with $5 \mathrm{gpl}$ enzyme and $10 \mathrm{gpl}$ common salt at $60 \mathrm{oC}$ for $2 \mathrm{~h}$.

Scouring. The desized fabric is treated with $2.5 \%$ sodium hydroxide, $1.5 \%$ sodium carbonate and $0.5 \% \mathrm{NP}-100$ at the boil for $6 \mathrm{~h}$.

Bleaching. The scoured fabric is bleached with $1 \% \mathrm{H} 2 \mathrm{O} 2(50 \%)$ at $80 \mathrm{oC}$ for $1 \mathrm{~h}$.

\subsubsection{Antimicrobial activity}

After confirming the antimicrobial activity of finished fabrics, the next step was to determine their minimum strength, which could inhibit microbial growth. For that we determined the minimum inhibitory concentration (MIC) of the finished fabric. To evaluate the antibacterial activity, AATCC test method 90-1970, the agar plate method, was employed.

\subsection{Comfort Eye's Swathe}

We design Eye's swathe to protect the babies' ayes of light and fluorescence while living in incubator, the analysis of experimental results with the models could provide useful information on Eye's swathe Surface structural design for the comfort performance improvement. Such as: Higher surface wetting tension led to higher capillary rise over a long wicking period. Vertical wicking comfort related vertical wicking behaviors in nonwoven (Mater-Bi) and cotton fabrics widely used for design Eyes' swathe clothing. This had given results of shielding ability with respect to the ultraviolet radiation penetration, surface structure measurement.

\section{SUMMARY AND CONCLUSIONS}

Nano silver can be used effectively as an antimicrobial agent for cotton. The higher the concentration of antimicrobial agent, the larger the zone of inhibition in the cases of both Grampositive and Gram-negative bacteria. SEM study of antimicrobial-finished fabric reveals that a continuous polymer film has been formed on the fabric. The concentration of PVOH controls the bending length and crease recovery angle. The higher the concentration of $\mathrm{PVOH}$, the greater the bending length and crease recovery angle. Curing temperature and time have profound impacts on the tensile strength. The higher the curing temperature and time, the lower the tensile strength. We design only this prototype for eye's swathe and diaper from this obtained material of Mater-Bi® because it has advantages such as its degradation by microorganisms under different environmental conditions. The other contents are local materials which produced from other industries as waste. Modelling good behavior and being a good example is the best way to develop light safe behaviors in your children. Adaptive face segmentation method is proposed to locate and regularize face candidatures, which are based on luminance-piecewise skin-color distributions. It consists of three steps: Detect face candidatures based on luminance piecewise statistical skin-color model and Bayesian decision/relaxation., Regularize the face candidatures by spatial segmentation results., Evaluate face candidatures by using both shape and size. In the research, we investigated comfort related vertical wicking behaviors in nonwoven cotton and BioNonwoven fabrics (Mater-Bi) widely used for eye's swathe and diaper. To feel comfort in

IRTIIE Vol. 4, No. 4, 2016 ISSN 1314-8788 (print), ISSN 1314-8796 (online), doi: 10.15547/artte.2016.04.003 


\section{ARTTIE Y}

Ipplied Reseitrones in Technics, Technologies and Bductition

Journal of the Faculty of Technics and Technologies, Trakia University https://sites.google.com/a/trakia-uni.bg/artte/

incubators clothing, nonwoven fabric should absorb easily and evaporate rapidly fluid exuded from human body. To simulate and rationalize vertical wicking, semi-empirical models were developed. The major parameters of the model were transport coefficient (permeability), the driving force through pore (capillary pressure), and eye's swathe and diaper thickness. And also to rationalize the results with regards to raw materials, the surface wetting tension was derived. In highly porous nonwoven fabrics, vertical wicking mechanism was complex as the effect of gravitation force was significant. Higher surface wetting tension led to higher capillary rise over a long wicking period. The testing methods and analysis of experimental results with the models could provide useful information on eye's swathe and diaper structural design for the comfort performance improvement. The presented approach allows us taking into account the stacking and forming of the layers, both in the flow and structural analyses. In the case of flow analysis, this allows us accurately study the effect of a multilayer reinforcement structure (nesting deformation etc.) on Volume Vertical Wicking Diaper. The lattice method should be chosen for a numerical analysis of Efficiency through the reinforcement.

\section{ACKNOWLEDGMENT}

The author are grateful to Dr. R.-J. Mueller, researcher at Gesellschaft für Biotechnologische Forschung $\mathrm{mbH}$ ), Braunschweig, Germany for providing us with bioplastic films and Dr. EISayed B. Belal, Faculty of Agriculture, 33516 Kafrelsheikh University, Egypt.

\section{REFERENCES}

[1] A.I. Wasif and S.K. Laga, (2009)," USE OF NANO SILVER AS AN ANTIMICROBIAL AGENT FOR COTTON", AUTEX Research Journal, Vol. 9, No1, March 2009 @ A AUTEX.

[2] Achwal, W.B., Colourage, 58-59, (Jan. 2003).

[3] Arvanitoyannis I., Biliaderis C. G., H. Ogawa, and N. Kawasaki, Carbohyd. Polym., 36, 89 (1998).

[4] ASTM. D1388-96: Standard Test Method for (Stiffness) of fabrics: 1996.

[5] ASTM. D3776-96: standard test method for mass per unit area (Weight) of fabric: 1996.

[6] ASTM. D4910-07: Standard Tables of Body Measurements for Infants, Sizes 0 to 241, 100 Barr Harbor Drive,PO Box C700, West Conshohocken, PA 19428-2959,USA. : 2007.

[7] ASTM. D5729-97: (Standard Test Method for Thickness of Nonwoven Fabrics):1997.

[8] Bastioli C.: Properties and applications of Mater-Bi starch-based materials, Polymer Degradation and Stability, 59,:1998, 263-272.

[9] Booth.J.E: Principals of textiles testing, an introduction to physical Methods of testing textile fibers, Yarn and Fabrics. The third edition John E.Booth, 1968.published by Heywood books. London.: 1968.

[10] Budtova T., Navard P.: Swelling Kinetics of a Polyelectrolyte Gel in Water and Salt Solutions, Macromolecules, 31:1998. pp 8845-8850.

[11] Dae-Hyun Kim, Oh-Jin Kwon, Seong-Ryul Yang, and Jong-Shin Park, Preparation of Starch-based Polyurethane Films and Their Mechanical Properties, Fibers and Polymers 2007, Vol.8, No.3, 249-256.

[12] EINashar E.A.: Effect the design and materials of eyes' swathe dressing and diapers clothes for Infant's Incubator". The 3rd national conference of environment and health of society, Elmonovia University, Egypt: 2004.

[13] Freddi, G., Arai, T., Colonna, G.M., Boschi, A., and Tsukada, M., J Appl Polym Sci, 82, 3513 (2004). 


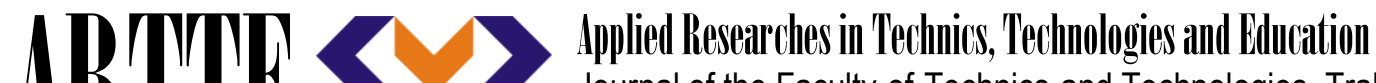 Journal of the Faculty of Technics and Technologies, Trakia University https://sites.google.com/a/trakia-uni.bg/artte/}

[14] Gibson P., Rivin D., Kendrick C.: Convection/Diffusion Test Method for Porous Textiles," International Journal of Clothing Science and Technology, Vol.12, No. 2, 2000.pp. 96112.

[15] Gross,R.A.,Kalra B.: Biodegradable polymers for the environment science, VOL 2972 , $803-807 .: 2002$.

[16] Gulrajani, M.L., Asian Dyer, 39 (2004).

[17] Lewin, M. and Sello, S.B., Handbook of Fiber Science and Technology: Chemical Processing of Fibers and Fabrics, Functional Finishes, vol. II, Part B, Marcel Decker, NY (1984), pp. 144-210.

[18] McDowell, J.W.: Better Medicine through Nonwovens-Nonwovens Applications in Medical Textiles. Nonwovens Industry, 10, 21-28.: 1991.

[19] Woodings C.: NF New Fibres, Available from (www.technica.net/NF). February,: 2001. 